\title{
Hdm2 is a ubiquitin ligase of Ku70-Akt promotes cell survival by inhibiting Hdm2-dependent Ku70 destabilization
}

\author{
V Gama ${ }^{1,2}$, JA Gomez ${ }^{1,2}$, LD Mayo ${ }^{3}$, MW Jackson ${ }^{4,5}$, D Danielpour ${ }^{2,5}$, K Song ${ }^{2,5}$, AL Haas ${ }^{6}$, MJ Laughlin ${ }^{1,5}$ and S Matsuyama ${ }^{\star, 1,2,5}$
}

Earlier, we have reported that $70 \mathrm{kDa}$ subunit of Ku protein heterodimer (Ku70) binds and inhibits Bax activity in the cytosol and that ubiquitin (Ub)-dependent proteolysis of cytosolic Ku70 facilitates Bax-mediated apoptosis. We found that Hdm2 (human homolog of murine double minute) has an ability to ubiquitinate Ku70 and that Hdm2 overexpression in cultured cells causes a decrease in Ku70 expression levels. An interaction between Ku70 and Hdm2 was shown by means of immunoprecipitation, whereas none could be shown between $80 \mathrm{kDa}$ subunit of Ku protein heterodimer and Hdm2. Vascular endothelial growth factor (VEGF) is known to inhibit endothelial cell (EC) apoptosis through an Akt-mediated survival kinase signal; however, the mechanism underlying this inhibition of apoptosis has not been fully elucidated. We found that VEGF inhibited cytosolic Ku70 degradation induced by apoptotic stress. It is known that Akt-dependent phosphorylation of Hdm2 causes nuclear translocation of Hdm2 followed by Hdm2-mediated inactivation of p53. We found that VEGF stimulated nuclear translocation of Hdm2 in EC and efficiently inhibited Ku70 degradation. We also found that constitutively active Akt, but not kinase-dead Akt, inhibited Ku70 degradation in the cytosol. Furthermore, Ku70 knockdown diminished antiapoptotic activity of Akt. Taken together, we propose that Hdm2 is a Ku70 Ub ligase and that Akt inhibits Bax-mediated apoptosis, at least in part, by maintaining Ku70 levels through the promotion of $\mathrm{Hdm} 2$ nuclear translocation.

Cell Death and Differentiation (2009) 16, 758-769; doi:10.1038/cdd.2009.6; published online 27 February 2009

Apoptosis is the physiological process by which the body eliminates unwanted cells, for example, those that are overgrown, mutated, or infected by parasitic organisms. ${ }^{1}$ Irregularities in apoptosis control can lead to health problems such as cancer and degenerative diseases. Therefore, understanding the mechanism underlying apoptosis is essential for the development of therapies for treating such diseases. Bax is expressed in nearly all cell types, and it is an important mediator of the intrinsic cell death pathway activated by DNA damage as well as other cellular stresses; ${ }^{2}$ however, its mechanism of activation remains enigmatic. On apoptotic stress (e.g. staurosporin (STS), etoposide (etopo), or doxorubicin treatments), Bax undergoes a conformational change in the cytosol exposing its $\mathrm{N}$-terminus to the molecular surface by an unknown mechanism. ${ }^{3}$ This change is known to promote mitochondrial translocation of $\mathrm{Bax}^{3}$ At the outer membrane of mitochondria, Bax stimulates the release of apoptogenic factors (e.g. cytochrome $c$ (cyto $c$ ), HtrA2/Omni, Endo G, and AIF) (reviewed by Scorrano and Korsmeyer ${ }^{4}$ ). Earlier, we found that Ku70 $(70 \mathrm{kDa}$ subunit of $\mathrm{Ku}$ protein heterodimer) binds Bax in the cytosol inhibiting its translocation to mitochondria. ${ }^{5-7}$ This anti-Bax activity of Ku70 has already been confirmed by others. ${ }^{8-13} \mathrm{Ku} 70$ is a ubiquitously expressed protein localized in both the nucleus and cytoplasm. In the nucleus, Ku70 is known to play an essential role in non-homologous end-joining (NHEJ) repair of DNA doublestrand breaks (reviewed by Morio and $\mathrm{Kim}^{14}$ ). Our laboratory and others have shown that cytosolic Ku70 has an anti-Bax activity that is independent from its DNA repair activity in the nucleus. ${ }^{5,8-13,15,16}$

Earlier, we reported that apoptotic stresses induce Ku70 destabilization in the cytosol by stimulating Ku70 ubiquitination. ${ }^{17}$ On the basis of this finding, we hypothesize that such loss of Ku70 activity is a critical mechanism activating Bax.

\footnotetext{
${ }^{1}$ Division of Hematology-Oncology, Department of Medicine, Case Comprehensive Cancer Center, Case Western Reserve University, Cleveland, OH, USA; ${ }^{2}$ Department of Pharmacology, Case Comprehensive Cancer Center, Case Western Reserve University, Cleveland, OH, USA; ${ }^{3}$ Department of Pediatrics, Herman B. Wells Center for Pediatrics Research, Melvin and Bren Simon Cancer Center, Indiana University School of Medicine, Indianapolis, IN, USA; ${ }^{4}$ Department of Pathology, Case Comprehensive Cancer Center, Case Western Reserve University, Cleveland, OH, USA; ${ }^{5}$ Division of General Medical Science-Oncology, Case Comprehensive Cancer Center, Case Western Reserve University, Cleveland, OH, USA and ${ }^{6}$ Department of Biochemistry and Molecular Biology, Louisiana State University School of Medicine, New Orleans, LA, USA

*Corresponding author: S Matsuyama, Division of Hematology/Oncology, Department of Medicine, Case Comprehensive Cancer Center, Case Western Reserve University, 2103 Cornell Rd, Cleveland, OH 44106, USA. Tel: + 21636858 32; Fax: + 21636889 19; E-mail: shigemi.matsuyama@ case.edu Keywords: Akt; apoptosis; Bax; Hdm2; Ku70; ubiquitin

Abbreviations: DMEM, Dulbecco's modified Eagle's medium; EC, endothelial cell; Etopo, etoposide; FBS, fetal bovine serum; GST, glutathione S-transferase; HBSS Hank's balance saline solution; Hdm2, human homolog of murine double minute; HEK293 (or 293T) cells, human embryonic kidney 293 (or 293T) cells; HUVEC, human umbilical vein endothelial cell; IgG, immunoglobulin G; Ku70, 70 kDa subunit of Ku protein heterodimer; Ku80, $80 \mathrm{kDa}$ subunit of Ku protein heterodimer; Mdm2, mouse double minutes 2; MEF, mouse embryonic fibroblast; PBS, phosphate-buffered solution; PFA, paraform aldehyde; PMSF, phenylmethylsulfonyl fluoride; SDS-PAGE, sodium dodecyl sulfate-polyacrylamide gel electrophoresis; STS, Staurosporin; Ub, ubiquitin; VEGF, vascular endothelial growth factor

Received 22.2.08; revised 09.12.08; accepted 29.12.08; Edited by J Silke; published online 27.2.09
} 
Ku70 acetylation is another mechanism that releases Bax from Ku70. ${ }^{9,16}$ As acetylation does not cause degradation of the target protein as ubiquitination does, acetylation-mediated Ku70 inactivation may represent a reversible mechanism to increase cellular sensitivity to Bax on a temporary basis. In fact, SIRT1 (human homolog of silent information regulator gene 1) and 3 have been reported to restore anti-Bax activity of Ku70 by deacetylating Ku70, 6,9,13,18 Ubiquitin (Ub)-dependent Ku70 proteolysis is irreversible. Therefore, Ku70 ubiquitination will generate cellular conditions that are more susceptible to Bax activation than those that would occur through Ku70 acetylation. To better understand the molecular mechanism of Bax activation, identification of enzyme(s) catalyzing Ku70 ubiquitination is necessary.

Here we show that Ku70 is a substrate for human homolog of murine double minute $(\mathrm{Hdm} 2)$ and mouse double minutes 2 (Mdm2) Ub ligases. Hdm2 is a human homolog of mouse p53 Ub ligase, Mdm2, and these enzymes are known to be negative regulators of $\mathrm{p} 53 .^{19,20}$ It has been shown that phosphorylation of $\mathrm{Hdm} 2$ by the survival kinase pathway (e.g. Akt) facilitates the nuclear localization of Hdm2. ${ }^{21,22}$ In this case, Hdm2 ubiquitinylates p53 in the nucleus, and inhibits p53-dependent cellular events such as cell cycle arrest and cell death. ${ }^{21,22}$ However, if the survival kinase signal is insufficient, Hdm2 remains unphosphorylated, stays in the cytosol, ${ }^{23}$ leaving p53 free to activate its target genes, including Bax. ${ }^{24}$ This study shows that cytosolic retention of Hdm2 enhances induction of apoptosis by decreasing cytosolic Ku70 and that Akt-mediated nuclear translocation of $\mathrm{Hdm} 2$ protects cytosolic Ku70 from degradation. We propose that the balance of survival kinase signal and DNAdamage-response signal determines cellular fate with respect to living or dying, at least in part, through the regulation of the Ku70-Bax interaction, which is under the control of Akt and $\mathrm{Hdm} 2$.

\section{Results}

Genotoxic stress induces Ku70 proteolysis in the cytosol. Earlier, we have reported that genotoxic stress induces Ku70 proteolysis through the stimulation of the Ub-dependent proteolytic pathway, ${ }^{17}$ suggesting that DNA damage activates a Ku70 ubiquitinylating enzyme. As shown in Figure 1a, we confirmed that genotoxic treatments (etopo and doxorubicin) decreased Ku70 levels in human umbilical vein endothelial cells (HUVECs). We also confirmed that small interfering RNA (siRNA)-mediated Ku70 knockdown ${ }^{25}$ increased the sensitivity of HUVECs to etopo (Figure $1 \mathrm{~b}$ and c) and STS (not shown). This is consistent with earlier observations in other cell types showing that Ku70 has antiapoptotic activity. ${ }^{6,7,9,11}$

As Hdm2 is a Ub ligase which is activated by DNA damage (reviewed by Meek and Knippschild ${ }^{26}$ ), we became interested in examining whether $\mathrm{Hdm} 2$ is involved in Ku70 ubiquitination caused by genotoxic stress. First, we analyzed the timedependent changes in Ku70 and Hdm2 protein levels after genotoxic stress (doxorubicin) treatment in primary cultured mouse embryonic fibroblasts (MEFs) (Figure 1d) and HUVECs (Figure 1e). In both cells types, Ku70 destabilization occurred after the significant increase of Mdm2 or Hdm2 expression. In the case of HUVECs, Hdm2 level increased until $16 \mathrm{~h}$ of the treatment, but started to decline from $24 \mathrm{~h}$ onward (Figure 1e), probably due to its auto-ubiquitination activity (reviewed by Meek and Knippschild ${ }^{26}$ ). Although $\mathrm{Hdm} 2$ levels showed a decrease after $24 \mathrm{~h}$ of doxorubicin treatment, p53 level decrease became evident after $48 \mathrm{~h}$ of treatment suggesting that $\mathrm{Hdm} 2 \mathrm{Ub}$ ligase activity is operative after $24 \mathrm{~h}$ of treatment. This is the same time at which Ku70 levels started to decline.

Hdm2 is a Ku70 ubiquitinylating enzyme. To examine whether Hdm2 induces Ub-dependent Ku70 proteolysis, we determined the ability of Hdm2 to control both Ku70 levels and Ku70 ubiquitination in vivo (cultured cells) and in vitro (recombinant proteins). Hdm2 overexpression caused a significant decrease of Ku70 levels in HUVECs (Figure 2a). Hdm2 mutant lacking Ub ligase activity (C464S mutant) ${ }^{27}$ did not influence Ku70 levels (Figure 2a) suggesting that the $\mathrm{Ub}$ ligase activity of $\mathrm{Hdm} 2$ is required for Ku70 destabilization. When proteasome activity was inhibited and HA-tagged Ub were expressed in HEK293 (human embryonic kidney 293 cells) cells, Hdm2-induced Ku70 ubiquitination was detected (Figure 2b). Ku70 levels of $m d m 2^{-/-}\left(p 53^{-/}\right)$MEFs were significantly higher than those observed in $m d m 2^{+/+}\left(p 53^{-/}\right)$ MEFs (Figure 2c), supporting the hypothesis that Mdm2 plays a role to destabilize Ku70. Furthermore, we found that recombinant $\mathrm{Hdm} 2$ ubiquitinated recombinant Ku70 proteins in vitro (Figure 2d, Supplementary Figure 1). The interaction between $\mathrm{Hdm} 2$ and $\mathrm{Ku} 70$ was confirmed by coimmunoprecipitation of endogenous proteins from cell lysates (Figure 2e). Importantly, no interaction between $\mathrm{Hdm} 2$ and Ku80 ( $80 \mathrm{kDa}$ subunit of Ku protein heterodimer) was detected (Figure 2e), an observation that further supports the specificity of Ku70-Hdm2 interaction. This interaction was also detected when purified recombinant proteins were used (Figure 2f). These results indicate that $\mathrm{Hdm} 2$ is a Ku70 Ub ligase. Moreover, Nutlin-3, an Hdm2 inhibitor blocking Hdm2-dependent p53 ubiquitination, disrupted Ku70-Hdm2 interaction in vitro (Figure 3a) and inhibited doxorubicin-induced Ku70 level decrease in HUVECs (Figure 3b). These results suggest that a Nutlin3-sensitive domain of $\mathrm{Hdm} 2$ is required for $\mathrm{Ku} 70$ destabilization. Interestingly, Nutlin-3 has been reported to show cytoprotective effects in non-transformed cells and certain types of tumor cell lines, ${ }^{28,29}$ contrary to its known effect in Hdm2-addictive cancer cells. ${ }^{30}$ We also observed that Nutlin-3 suppressed doxorubicin-induced apoptosis in HUVECs (Figure 3c). In particular cell types, such as HUVECs, proliferating mouse fibroblasts ${ }^{28}$ and human kidney cells, ${ }^{29}$ Nutlin-3 may be able to attenuate apoptosis induction, at least in part, by maintaining Ku70 levels.

VEGF activates Akt and inhibits Ku70 proteolysis. Vascular endothelial growth factor (VEGF) is a tropic factor for endothelial cells (ECs) and was reported to inhibit EC apoptosis through the activation of the Akt pathway. ${ }^{31}$ We confirmed that VEGF protected ECs against doxorubicin-induced apoptosis (Figure $4 \mathrm{a}$ and b). VEGF prevented Ku70 degradation in doxorubicin-treated cells 


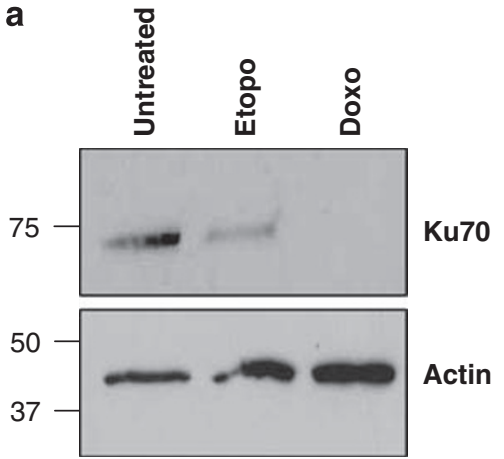

b

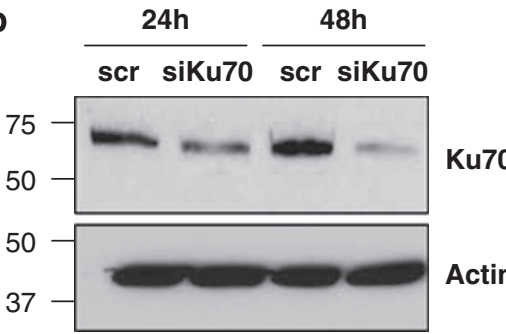

\section{d}
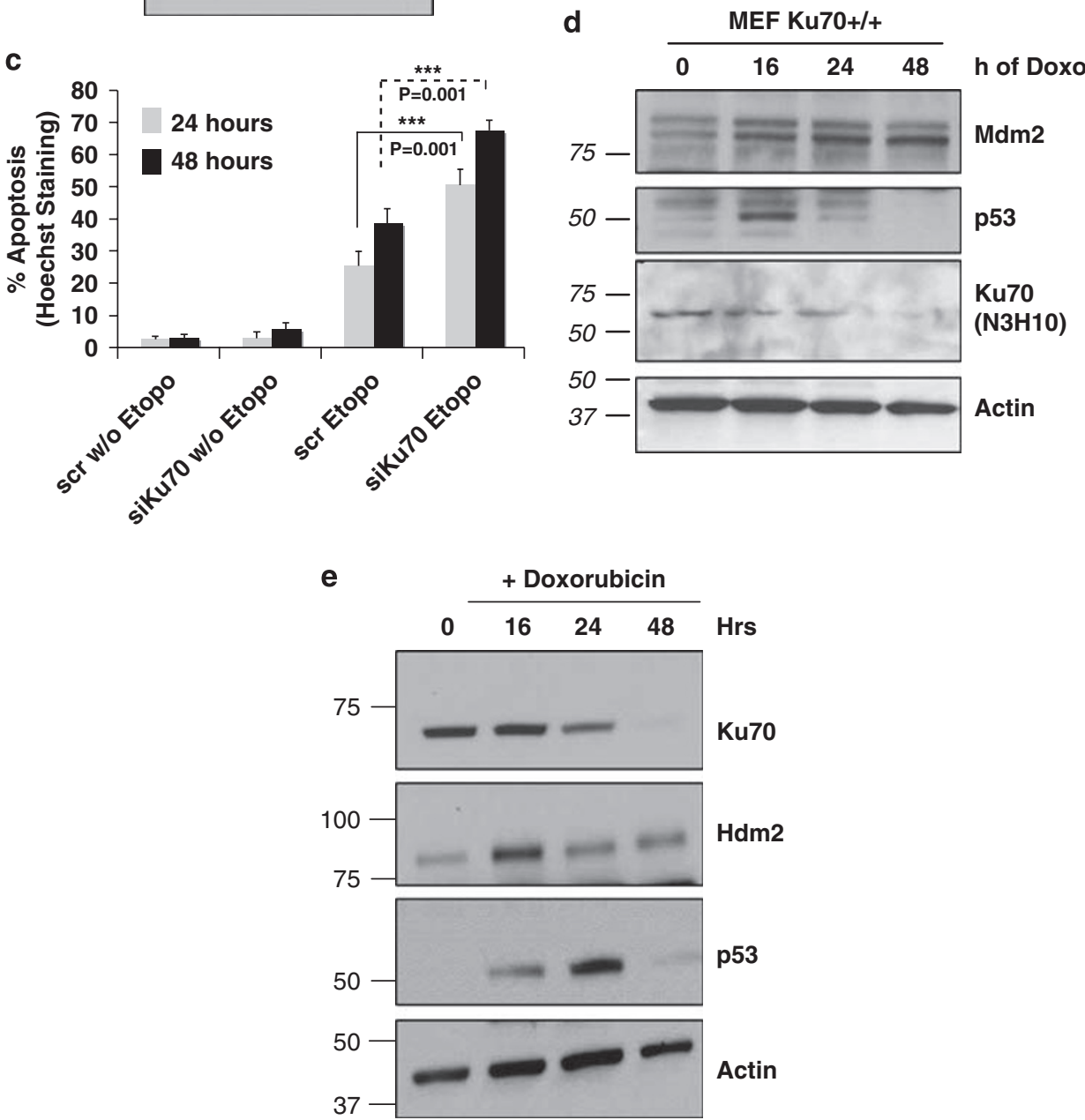

Figure $1 \mathrm{Ku} 70$ decreases in response to genotoxic stress. (a) HUVECs were seeded in six-well plates and $24 \mathrm{~h}$ later treated with $10 \mu \mathrm{M}$ etoposide (etopo) or $1 \mu \mathrm{M}$ doxorubicin (doxo) for $24 \mathrm{~h}$. After incubation, cells were collected and $2 \mu \mathrm{g}$ of total protein were examined by western blotting with anti-Ku70 (N3H10) and anti-actin antibodies. (b) HUVECs were plated onto six-well plates at $1.2 \times 10^{5}$ cells per well and transfected with the indicated siRNAs as described in Materials and Methods. Results from 24 and $48 \mathrm{~h}$ post-transfection are shown. (c) Forty-eight hours after siRNA transfection, HUVECs were treated with $10 \mu \mathrm{M}$ etopo for 24 and $48 \mathrm{~h}$. Apoptosis was detected by nuclear fragmentation using Hoechst-dye nuclear staining. Data shown are averages ( \pm S.E.) $(n=300$ cells per condition in triplicate) of three independent experiments. (d) MEFS $\left(k u 70^{+/+}\right)$were seeded in six-well dishes and treated with $1 \mu \mathrm{M}$ doxorubicin for the times shown in the figure. Cells were then collected and western blot analysis was performed with anti-Mdm2, anti-p53, anti-Ku70, and anti-actin antibodies. (e) HUVECs were seeded in six-well plates and $24 \mathrm{~h}$ later treated with $1 \mu \mathrm{M}$ doxorubicin for the times shown in the figure. After incubation at specific times, cells were collected and examined by western blotting with anti-Ku70, anti-Hdm2, anti-p53, and anti-actin antibodies

(Figure 4c) suggesting that VEGF protects ECs, at least in part, by inhibiting Ku70 proteolysis. It has been reported that Akt phosphorylates Hdm2. ${ }^{21,32}$ As shown in Figure 4c, we confirmed that VEGF, which activates Akt, induced Hdm2 phosphorylation on serine 166 .
VEGF promotes nuclear translocation of $\mathbf{H d m 2}$. It is known that Akt-dependent phosphorylation of $\mathrm{Hdm} 2$ induces the translocation of $\mathrm{Hdm} 2$ from the cytosol to the nucleus. ${ }^{21,32}$ Therefore, VEGF is expected to enhance nuclear localization of $\mathrm{Hdm} 2$ through Akt activation. As 
a
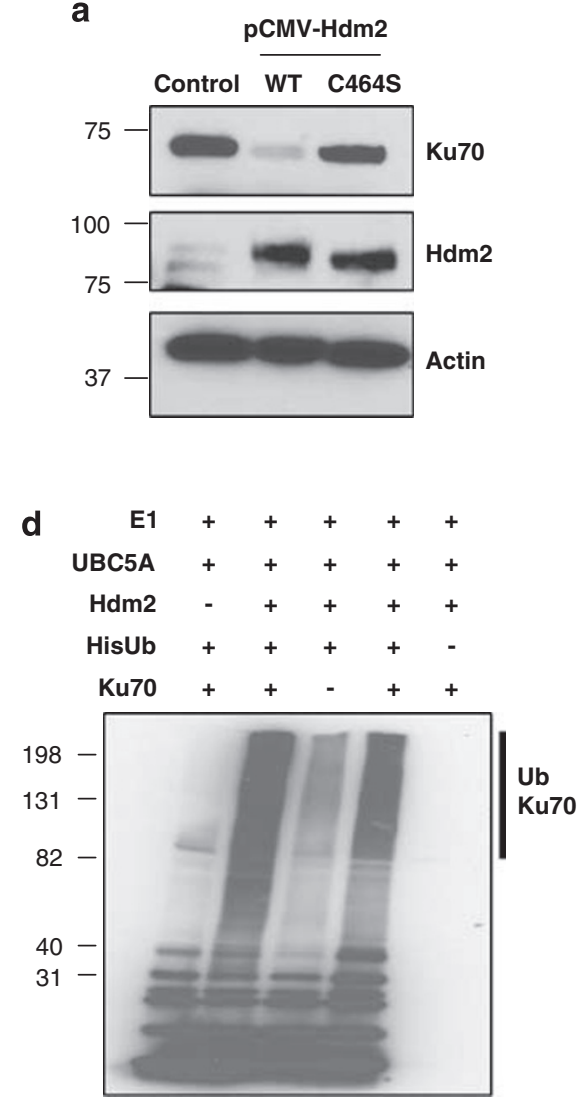

b
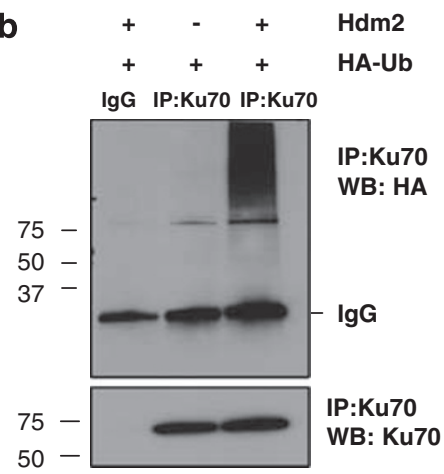

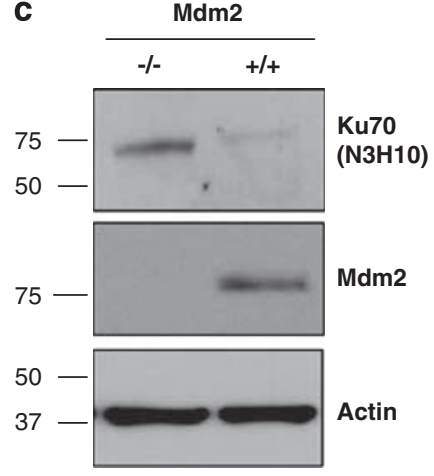

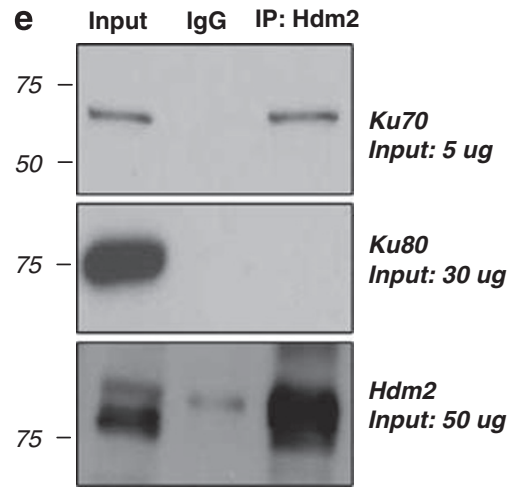

f

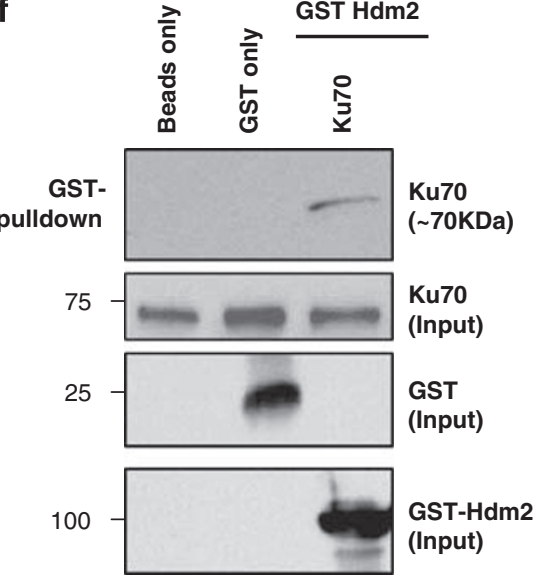

Figure $2 \mathrm{Hdm} 2$ is a ubiquitin ligase of Ku70. (a) Hdm2 overexpression decreased Ku70 levels. HUVECs were transfected with pCMV vector, pCMVHdm2-wt, or pCMVHdm2-C464S (dead ligase) and cultured for $16 \mathrm{~h}$. Cells were then collected and analyzed by western blot using anti-Ku70, anti-Hdm2, and anti-actin antibodies. (b) HEK293 cells were transfected with pCMVHdm2-wt and HA-tagged Ubiquitin-wt constructs as indicated. Twenty-one hours later, cells were treated with $5 \mu \mathrm{M}$ MG132 for $3 \mathrm{~h}$; cells were then collected and lysed in RIPA buffer. Immunoprecipitation with anti-Ku70 antibody (H308) was performed as indicated in Materials and Methods, and western blot was carried out with anti-Ku70 (N3H10) and anti-HA antibody. Mouse lgG was used as control for the immunoprecipitation. (c) Ku70 level in mdm2 ${ }^{+/+}$and mdm2 ${ }^{-1-}$ MEFs.

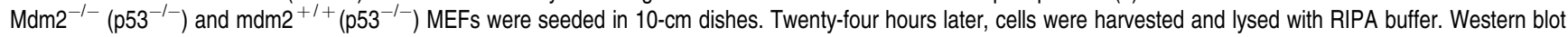
analysis was then performed with anti-Ku70 (N3H10 antibody). Mdm2 antibody was used to confirm Mdm2 levels. (d) In vitro ubiquitination assay of Ku70 by Hdm2. Reaction volumes were prepared as indicated in Material and Methods and incubated for $2 \mathrm{~h}$ at $37^{\circ} \mathrm{C}$ in the presence or absence of $10 \mu \mathrm{M}$ unlabeled ubiquitin. Reactions were quenched with $50 \mu \mathrm{l}$ of Laemmli sample buffer containing $2 \%(\mathrm{v} / \mathrm{v}) \beta$-mercaptoethanol and boiled for $5 \mathrm{~min}$. Western blot was performed with anti-ubiquitin antibody. (e) Coimmunoprecipitation of $\mathrm{Hdm} 2$ and Ku70. HUVECs were collected and immunoprecipitation with anti-Hdm2 antibody was performed in Chaps buffer. Western blot analysis was carried out using anti-Ku70 antibody, anti-Ku80 antibody, and anti-Hdm2 antibody. (f) GST pull-down assay using GST-tagged Hdm2 and recombinant Ku70 was performed using the ProFound ${ }^{\mathrm{TM}}$ pull-down GST protein/protein interaction kit (Pierce) as described by the manufacturer. Interaction was analyzed by western blotting using anti-Ku70 antibody

expected, Hdm2 was found both in the cytosol and nucleus in the absence of VEGF (Figure 5a, left upper panel). VEGF treatment enhanced nuclear translocation of $\mathrm{Hdm} 2$ regardless of the presence of genotoxic stress (doxorubicin) (Figure 5a, right upper and lower panels). Figure 5b shows the result of quantitative analysis of cells with different distribution of $\mathrm{Hdm} 2$. This quantitative analysis confirmed that VEGF promotes nuclear localization of Hdm2 in ECs.

Akt inhibits Ku70 proteolysis in the cytosol. Consistent with earlier studies, ${ }^{31}$ transient overexpression of constitutively active Akt (Myr-Akt), but not kinase-dead Akt (K179M-Akt), protected HeLa cells (Figure 6a) and HUVECs (Figure 6b, Supplementary Figure $2 a$ and b) from etopo- and doxorubicin-induced apoptosis. As Akt is required for cytoprotection by VEGF, 21,32 we examined whether Akt activation is sufficient to suppress Ku70 proteolysis in cells treated by genotoxic stress. We found that constitutively active Akt, but not kinase-dead Akt, suppressed Ku70 disappearance in the cytosol of etopo-treated cells (Figure $6 \mathrm{c}$ and d). Next, we examined the effects of Akt on subcellular localization of $\mathrm{Hdm} 2$ in doxorubicin-treated HUVECs (Supplementary Figure 3). Hdm2 localized both in the cytosol and nucleus when constitutive-active Akt was not expressed, whereas Hdm2 localized mainly in the nucleus when the active Akt was expressed. These results imply that Akt, which is activated by VEGF in HUVECs, inhibited Hdm2dependent Ku70 degradation in the cytosol by enhancing nuclear relocalization of $\mathrm{Hdm} 2$ from the cytosol.

Ku70 is required for Akt to protect cells from genotoxic stress. As Akt inhibits Ku70 destabilization, we hypothesized that Akt inhibits Bax-mediated apoptosis, at least in part, by maintaining Ku70 levels. To examine this hypothesis, the effect of Akt on cell survival was compared 
a IP Input lgG $\alpha \mathrm{Hdm} 2 \underset{-}{\alpha \mathrm{Hdm} 2} \mathrm{+} 20 \mathrm{uM}$ Nutlin

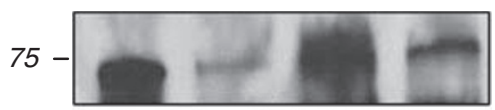

WB: Ku70

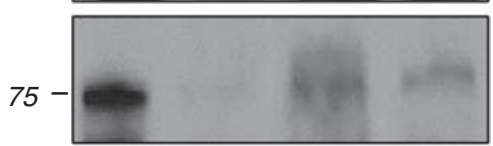
Long Exposure

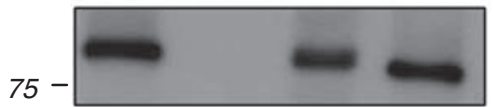

WB: Ku70

Short Exposure

WB: Hdm2
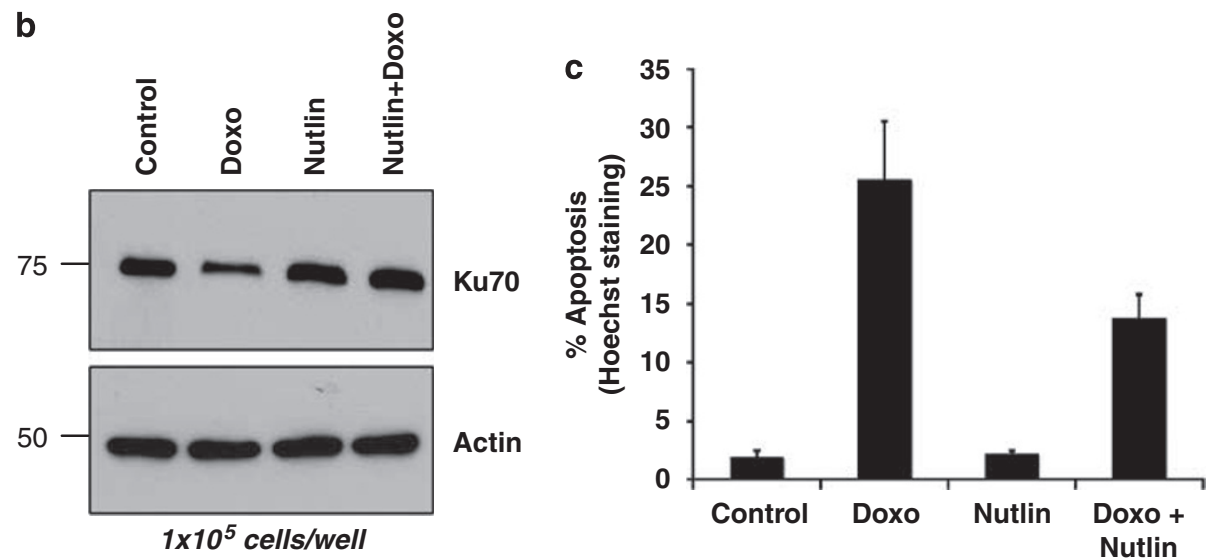

Figure 3 Nutlin-3 disrupts the Ku70-Hdm2 interaction. (a) Nutlin-3 inhibits Ku70-Hdm2 interaction. Fifty nanograms of recombinant Hdm2 were incubated with beads preabsorbed with $\mathrm{Hdm} 2$ antibody, for $2 \mathrm{~h}$. After incubation, $50 \mathrm{ng}$ of recombinant Ku70 (Enzymax) were added in the presence of $20 \mu \mathrm{M}$ Nutlin-3 when indicated. After additional $2 \mathrm{~h}$ incubation, beads were washed and samples were analyzed by western blotting using anti-Ku70 (H308) or anti-Hdm2 (2A10) antibodies. (b) Nutlin-3 inhibited doxorubicininduced Ku70 proteolysis. Cells prepared as in (b) were lysed and $2 \mu \mathrm{g}$ of total protein were analyzed by western blotting using anti-Ku70 (N3H10) and anti-actin antibodies. (c) Nutlin protected HUVECs from doxorubicin-induced apoptosis. Cells $\left(1 \times 10^{5}\right)$ were seeded in six-well dishes. Twenty-four hours later, cells were treated with $5 \mu \mathrm{M}$ nutlin and after $30 \mathrm{~min}, 1 \mu \mathrm{M}$ doxorubicin was added to corresponding wells. Apoptosis was detected $24 \mathrm{~h}$ later by nuclear fragmentation using Hoechst nuclear staining. Data shown are average $( \pm$ S.E.) of triplicated samples ( 300 cells per condition in triplicate)

between Ku70-proficient and -deficient cells. As shown in Figure 7, Akt could not inhibit apoptosis induced by etopo and STS (Figure 7a, b and d) in Ku70-deficient cells. Ku70 deficiency did not induce a significant increase of Bax expression and it did not decrease Bcl-2 (Figure 7c and e). Therefore, an alteration of Bax and Bcl-2 levels is not likely the reason why Akt lost its cytoprotective activity in Ku70deficient cells.

Akt maintains the Ku70-Bax interaction. As shown earlier by us and others (reviewed by Gomez et al. ${ }^{7}$ ), Ku70 binds Bax and inhibits Bax activation. The conformational change of Bax associated with its activation can be detected using an antibody that recognizes the $N$-terminus of $\mathrm{Bax}(6 \mathrm{~A} 7$ antibody). ${ }^{3}$ We have confirmed that the interaction of Ku70 and Bax was diminished when cells were treated with etopo (Figure 8a, top panel). In this condition, an increase in the level of active Bax was detected by $6 A 7$ antibody (Figure 8a, second panel). Importantly, constitutively active Akt maintained the Ku70-Bax interaction and significantly attenuated Bax activation (Figure 8a). As shown in other experiments, etopo treatment decreased Ku70 levels, and Akt inhibited this Ku70 degradation (the third panel). In Ku70- null cells ( $k u 70^{-1-}$ MEFs), Akt was observed to have only a slight effect in suppressing the Bax conformation change (Figure 8b). These results further support our hypothesis that Akt inhibits Bax-mediated apoptosis, at least in part, by maintaining Ku70 levels.

\section{Discussion}

This study shows that Hdm2 plays a role as a mediator of apoptotic stress by decreasing cytosolic Ku70 levels. We also show evidence suggesting that Akt suppresses Bax-mediated apoptosis, at least in part, through inhibiting $\mathrm{Hdm} 2$-dependent cytosolic Ku70 proteolysis by promoting nuclear translocation of $\mathrm{Hdm} 2$ from the cytosol. On the basis of these observations, we propose two scenarios that determine cellular fate in response to genotoxic stress that activates p53 and Hdm2 (Figure 8c). DNA damage stimulates Ku70 ubiquitinylation through increasing Hdm2 levels in the cytosol, and Ku70 proteolysis promotes Bax-mediated apoptosis (scenario 1) (Figure 8c, right panel). However, if there is a sufficient survival kinase signal activating Akt, then Akt maintains cytosolic Ku70 levels by translocating Hdm2 into the nucleus, resulting in the stabilization of cytosolic Ku70 levels and a 
a

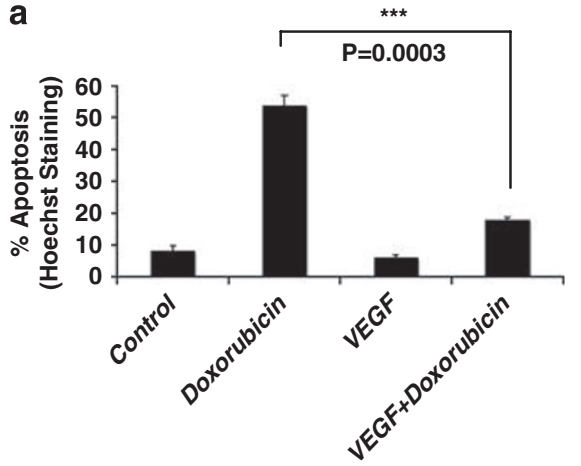

b

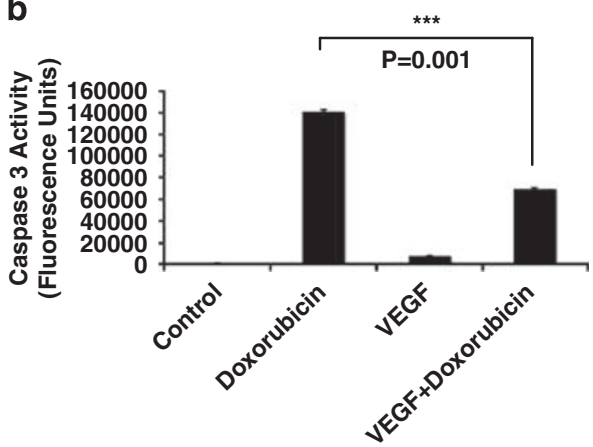

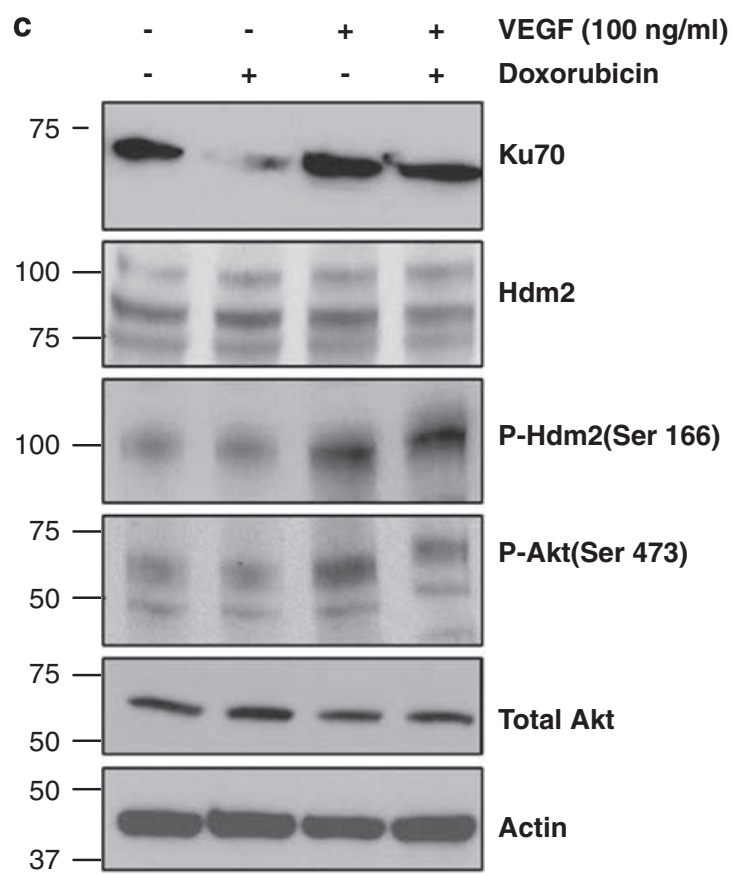

Figure 4 Trophic factor VEGF protects endothelial cells from apoptosis and inhibits Ku70 proteolysis. (a) VEGF inhibited doxorubicin-induced apoptosis, HUVECs were serum-starved for $15 \mathrm{~min}$ and treated with VEGF (100 ng/ml) for $2 \mathrm{~h}$. Doxorubicin was then added for additional $14 \mathrm{~h}$. Apoptosis was detected by nuclear fragmentation using Hoechst-dye nuclear staining, and (b) by caspase activation. Data represent average ( \pm S.E.) from three independent experiments. (c) VEGF inhibited Ku70-proteolysis induced by doxorubicin. HUVECs were seeded in 6 -cm dishes and $24 \mathrm{~h}$ later treated with VEGF (100 $\mathrm{ng} / \mathrm{ml})$ in serum-free media for $2 \mathrm{~h}$. Doxorubicin $(1 \mu \mathrm{M})$ was then added and cells were collected after additional $16 \mathrm{~h}$ incubation. Western blot analysis with anti-Ku70, anti-Hdm2, anti-phospho-Hdm2 (Ser 166, Akt-dependent phosphorylation site), anti-phospho-Akt (Ser 473), anti-total Akt, and anti-actin antibodies was performed. ${ }^{21}$ This is representative of three independent experiments

reduction in nuclear levels of p53 (Figure $8 c$, left panel). We propose that the Hdm2-dependent Ku70 ubiquitinylation mechanism provides an adjustable rheostat system determining cell survival or death by sensing the balance between survival kinase signal and the DNA-damage-response signal.

For years, the notion of Ku70 existing in a complex with $\mathrm{Ku} 80$ in a one-to-one ratio (reviewed by Morio and $\mathrm{Kim}^{14}$ ) and observations that Ku70 and Ku80 stabilize each other ${ }^{33,34}$ limited the possibilities of uncovering Ku70- or Ku80-specific mechanism regulating the turnover of these proteins. We found that $\mathrm{Hdm} 2$ binds to Ku70 and targets it for degradation, but not to Ku80 (Figure 2d and e). We reported that Ku80 as well as Ku70 are subjected to ubiquitination, ${ }^{17}$ implying the presence of an unidentified Ku80 Ub ligase(s). We propose that there are heterodimerization-dependent and -independent mechanisms controlling Ku protein levels. Importantly, concentrations of Ku70 and Ku80 are not equal, and Ku70 levels in the cytosol are much higher than those observed for Ku80 (Gama V, Gomez J, and Matsuyama S, unpublished data). This observation indicates the presence of heterodimerization-independent mechanism of Ku70 stabilization. As Hdm2 targets Ku70, but not Ku80, the regulation of Ku70 $\mathrm{Ub}$ ligase activity of $\mathrm{Hdm} 2$ will represent one of heterodimerization-independent mechanisms controlling Ku70 level.

How then does Ku70-Ku80 heterodimer formation protect $\mathrm{Ku}$ proteins from degradation? Ku70 and Ku80 form stable complexes with DNA in the nucleus (reviewed by Morio and $\mathrm{Kim}^{14}$ ) and this complex formation may prevent access of enzymes that induce proteolysis of Ku proteins. This study showed that cytosolic localization of Hdm2 stimulates Ku70 disappearance from the cytosol, whereas Akt-dependent nuclear translocation of $\mathrm{Hdm} 2$ did not cause a major decrease 

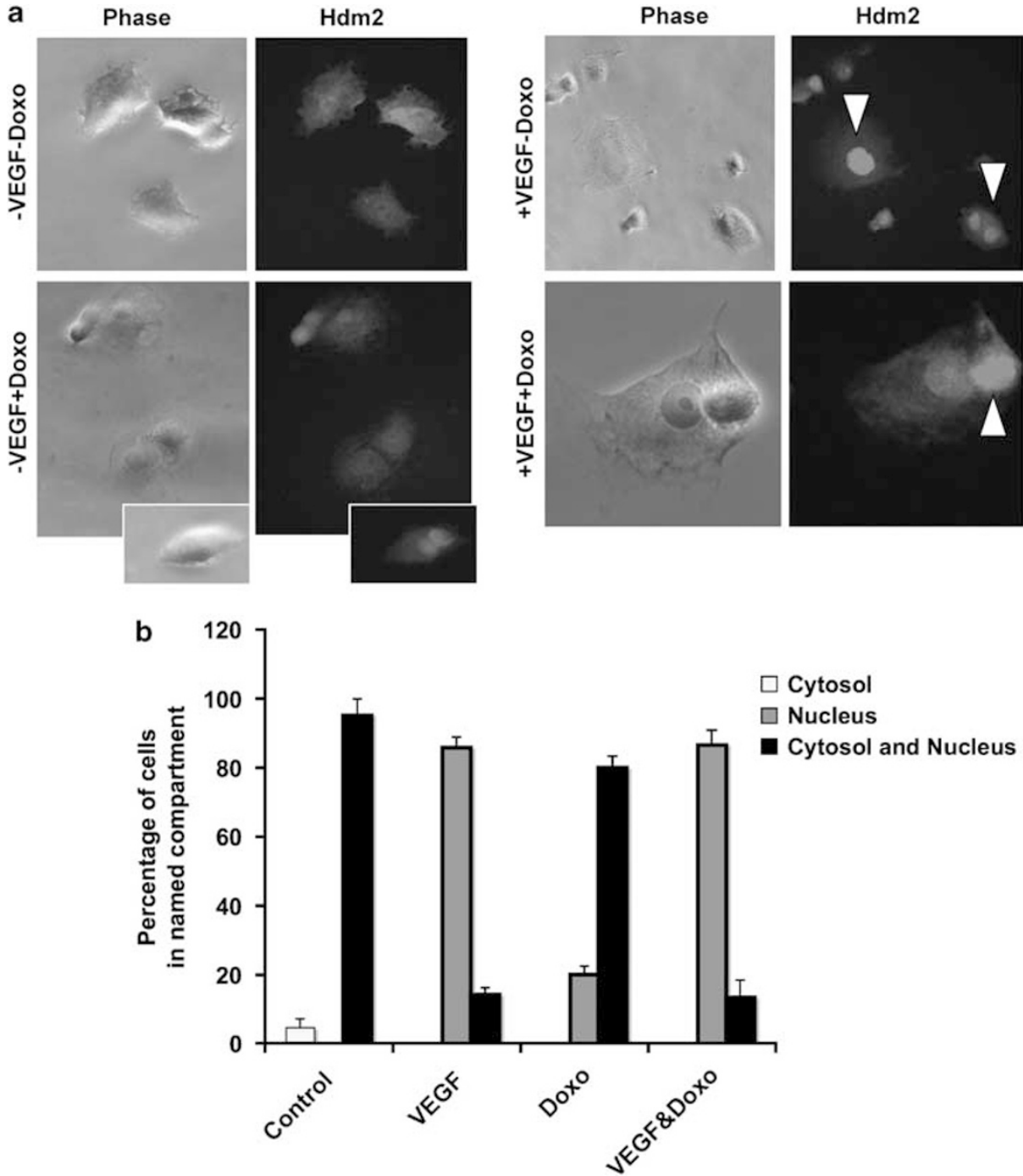

Figure 5 VEGF promotes nuclear translocation of Hmd2. (a) Immunohistochemical analysis. HUVECs were seeded on gelatin-coated 35-mm dishes. Cells were serumstarved for $15 \mathrm{~min}$ and treated with VEGF (100 ng/ml) for $2 \mathrm{~h}$. Doxorubicin was then added for $2 \mathrm{~h}$ and immunohistochemistry was performed as described earlier. After fixation of samples in 4\% PFA for $10 \mathrm{~min}$ and permeabilization with $0.2 \%$ Triton X-100, the cellular localization of Hdm2 was detected using a monoclonal antibody against Mdm2 (IF2). After extensive washing in PBS, the samples were further incubated with Texas-Red-conjugated goat anti-mouse lgG and examined under a fluorescent microscope. Arrows identify cells with $\mathrm{Hdm} 2$ nuclear localization. (b) Quantitative analysis of subcellular localization of Hdm2 detected by immunocytochemistry. In each sample, at least 100 cells were analyzed. Data represent averages $( \pm$ S.E.) of three independent experiments performed using duplicated samples

in nuclear levels of Ku70 (Figure 6c). Although further study is clearly needed, it is possible that a stable complex formation of Ku70-Ku80-DNA may protect Ku70 from Hdm2-mediated Ub-dependent degradation.

$\mathrm{Hdm} 2$ is a known oncogene, as $\mathrm{Hdm} 2$ negatively regulates tumor suppressor p53 and is highly expressed in several types of tumors. ${ }^{19,20,35}$ Earlier studies suggest the presence of p53-independent oncogenic activity of $\mathrm{Hdm} 2 .^{36} \mathrm{Ku} 70$ ubiquitinylating activity of $\mathrm{Hdm} 2$ may contribute to its p53independent oncogenic activity. The elevated levels of Hdm2 may cause a decrease in Ku70 supply from the cytosol, which may negatively influence Ku-dependent DNA repair activity in the nucleus. If this is the case, an elevated Hdm2 level may facilitate genomic instability by lowering Ku70 levels. In certain types of cancer cells, a temporary Ku70 decrease caused by an elevated Hdm2 level may facilitate acquisition of further mutations, and cancer cells may become resistant to apoptosis by an elevation of Ku70 levels through the hyperactivation of Akt that inhibits Ku70 proteolysis. This study focused on elucidating the mechanism of how Hdm2 controls the decision making process of cells to survive or die over a short period (1-2 days) of cellular life. Further studies will be necessary to investigate the biological significance of Ku70 ubiquitinylation by $\mathrm{Hdm} 2$ in tumorigenesis with respect to determining long-term effects of elevated Hdm2 on Ku70 levels and Ku-dependent DNA repair activity.

Akt is known as a cytoprotective kinase mediating the $\mathrm{PI}-3$ kinase pathway activated by growth factors and tropic factors (reviewed by Manning and Cantley $^{37}$ ). There are multiple mechanisms by which Akt inhibits apoptosis. For example, Akt inactivates proapoptotic factors by phosphorylation (e.g. Bad and caspase-9) and maintains cellular energy 
a

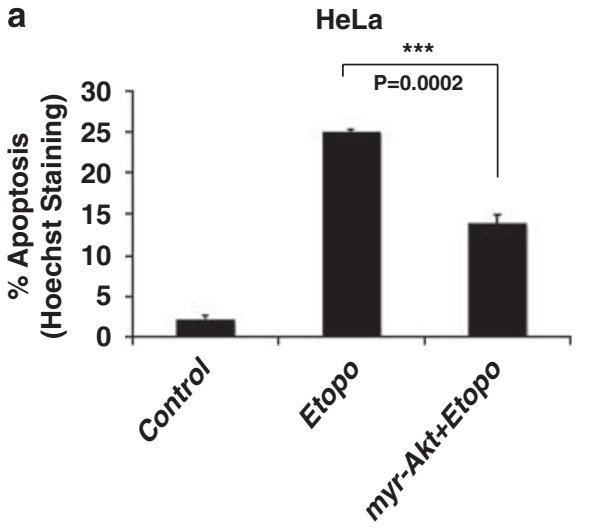

C

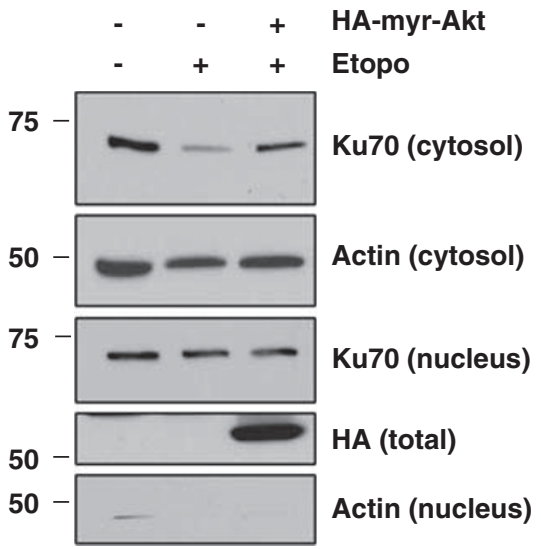

b

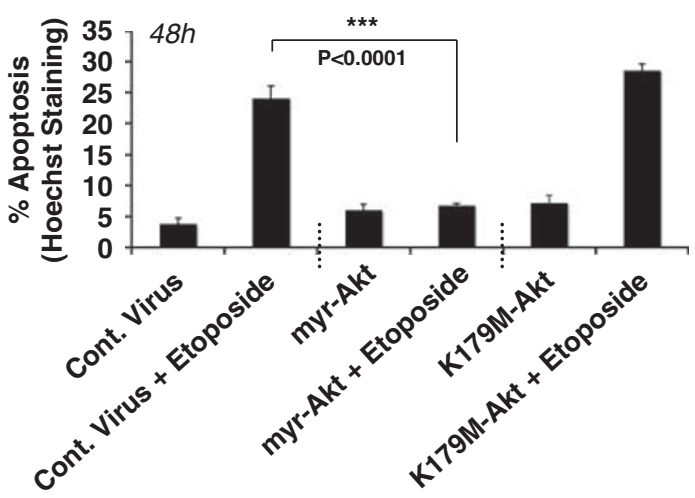

d

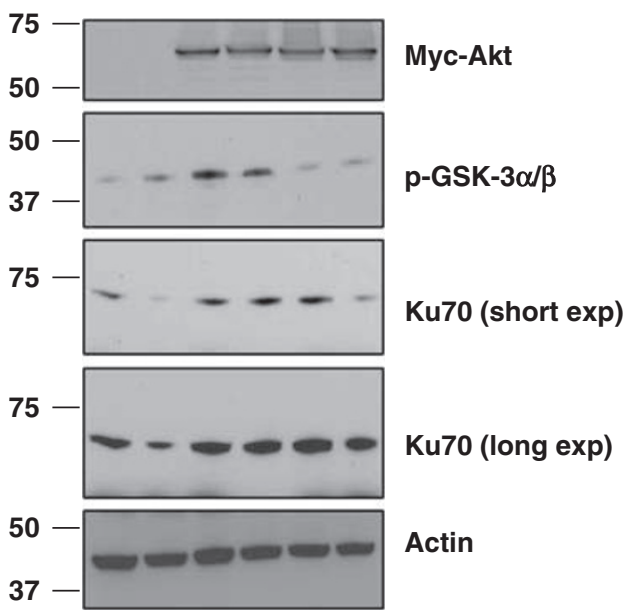

Figure 6 Akt protects cells from etoposide (etopo)-induced apoptosis and inhibits Ku70 degradation. (a) Akt inhibited etopo-induced apoptosis in HeLa cells. HeLa cells were transfected with control plasmid pcDNA3 (control) or plasmid expressing HA-Myr-Akt (myr-Akt). Twenty-four hours later transfection, cells were treated with $25 \mu \mathrm{M}$ etopo for additional $16 \mathrm{~h}$ and apoptosis was detected by nuclear fragmentation using Hoechst nuclear staining. Data represent average ( \pm S.E.) of three independent experiments (300 cells per sample were counted). (b) Akt inhibited etopo-induced apoptosis in HUVECs. HUVECs $\left(2 \times 10^{5}\right)$ per well were seeded in six-well plates. Next day, cells were infected using adenovirus expressing Akt constructs (Myc-Myr-Akt (constitutively active), Myc-K179M-Akt (dominant negative), or empty vector (control virus)). Twenty-four hours later, cells were extensively washed with Hank's buffer saline solution (HBSS) and then treated with $10 \mu \mathrm{M}$ etopo for $24 \mathrm{~h}$. Infection efficiency was almost $100 \%$ as shown in Supplementary Figure 2a. Data represent average ( \pm S.E.) of three independent experiments ( 300 cells per sample were counted) (c), Akt inhibited Etopo-induced Ku70 level decrease in HUVECs. Cells were treated as described in (a). After the treatment, cells were collected and subcellular fractionation was performed as described in Materials and Methods. Each fraction subjected to western blot and expression level of Ku70, actin, and HA-Akt was determined. (d) Akt inhibited etopo-induced Ku70 level decrease in HeLa cells. Cells were treated as described in (b). Cell lysates were subjected to western blot analysis and expression levels of Myc-Akt, phospho-GSK3, Ku70, and actin were determined

homeostasis by stimulating glycolysis (reviewed by Manning and Cantley $^{37}$ ). Earlier, it was shown that Akt suppresses activation (conformational change resulted in the exposure of the N-terminus) of Bax and mitochondrial translocation of Bax. ${ }^{38,39}$ However, the precise details of the mechanism by which Akt suppresses Bax activation remain unknown. This study showed a new mechanism by which Akt can protect the cell by suppressing Bax activation through maintaining cytosolic Ku70 levels. Interestingly, Akt was unable to protect Ku70-deficient cells from etopo (Figure 6) and STS (not shown). These results indicate that Ku70 is required for Akt to fully express its antiapoptotic activity. On tha basis of these and other observations in this study, we hypothesize that Akt inhibits Bax activation, at least in part, by suppressing Hdm2dependent Ku70 proteolysis. However, we concede that other interpretations may be possible. For example, Ku70 deficiency itself may lead to an increase of un-repaired genomic damage, which in turn may generate unexpected changes in the expression levels of molecules mediating Akt-dependent signals in Ku70-deficient cells. Further studies investigating the role of Ku70 in Akt-mediated cytoprotection will be needed to test our hypothesis. 

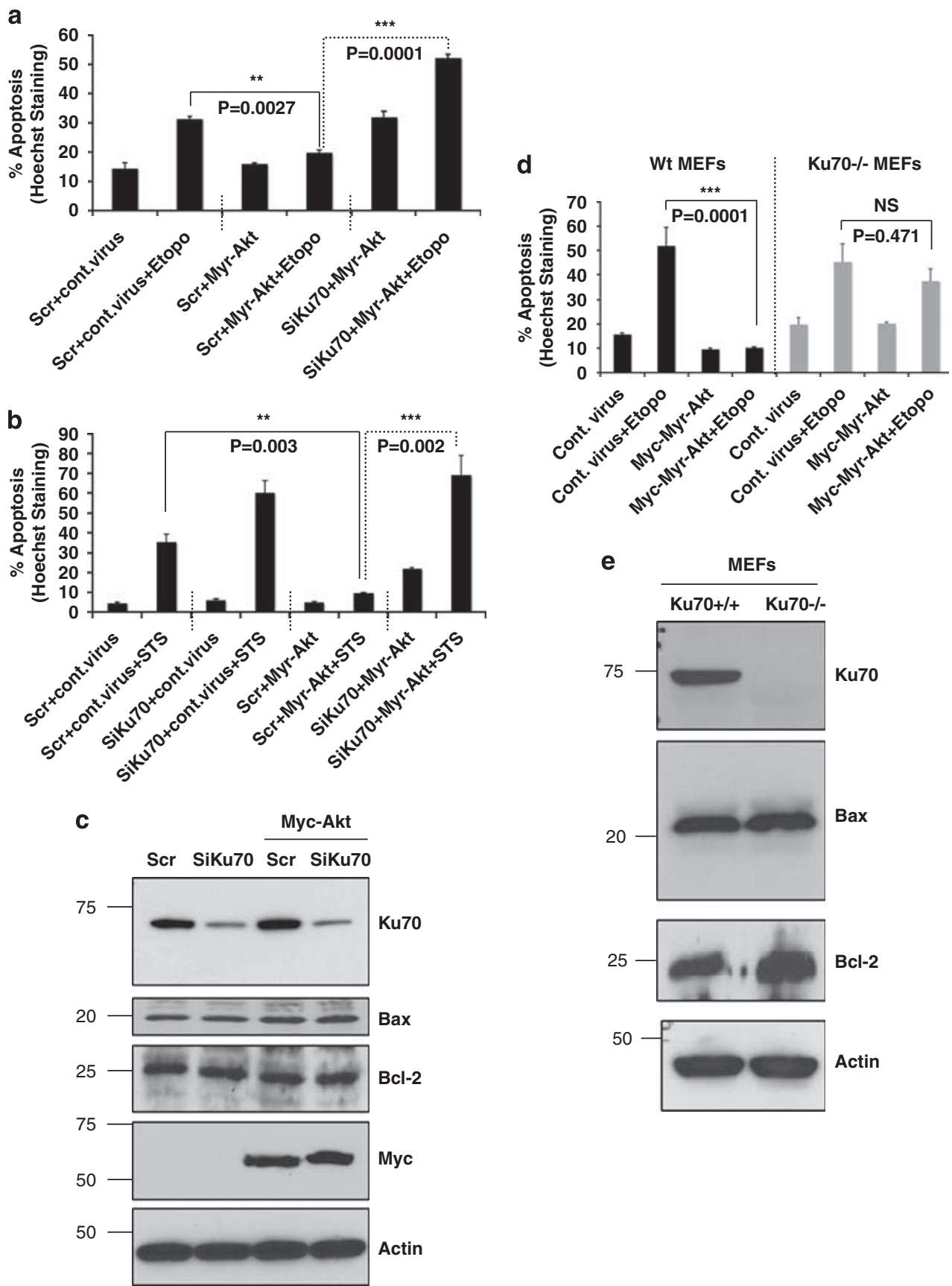

Figure 7 Ku70 is required for Akt to protect cells from genotoxic stress. (a and $\mathbf{b})$ Akt did not show cytoprotection in Ku70 siRNA-treated cells. HeLa cells were plated onto six-well plates at $1.2 \times 10^{5}$ cells per well and transfected with the Ku70 siRNA (SiKu70) or scrambled control RNA (Scr) as described. ${ }^{25}$ Twenty-four hours after transfection, cells were infected with adenovirus expressing Myc-Myr-Akt (constitutively active) and incubated additional $24 \mathrm{~h}$. Then, cells were treated with $25 \mu \mathrm{M}$ etoposide (etopo) (a) or $200 \mathrm{nM}$ staurosporin (STS) (b) for $16 \mathrm{~h}$, and apoptosis induction was determined by Hoechst-dye nuclear staining. Data represent average ( \pm S.E.) ( 300 cells per sample were counted) of triplicated experiments. (c) Ku70 siRNA successfully knocked down Ku70 in HeLa cells. Ku70 siRNA (SiKu70) and Myc-Akt were expressed in HeLa cells as described in (a), and western blotting analysis was performed with anti-Ku70, anti-Bax, anti-Bcl-2, anti-Myc, and anti-actin. (d) Akt did not show significant cytoprotective activity in Ku70-null MEFs. Wild-type and ku70 ${ }^{-1-}$ MEFs $\left(8 \times 10^{4}\right.$ cells per well) were seeded in 12 -well plates. Twenty-four hours later, cells were infected with adenovirus expressing Myc-Myr-Akt. The following day, cells were treated with $10 \mu \mathrm{M}$ etopo for additional $12 \mathrm{~h}$ and apoptosis was analyzed as described in Figure 1a. (e) Expression levels of Ku70, Bax, and Bcl-2 of wild-type and ku70 ${ }^{-1-}$ MEFs. Wild-type and ku70 ${ }^{-1-}$ MEFs were analyzed by western blotting with anti-Ku70 (N3H10), anti-Hdm2 (2A10), anti-p53, anti-Bax (N20), anti-Bcl-2, and anti-actin antibody

In summary, this study showed that $\mathrm{Hdm} 2$ is a Ku70 $\mathrm{Ub}$ ligase. This study also showed results suggesting that Akt inhibits Bax activation, at least in part, by maintaining Ku70 levels by inhibiting Hdm2-dependent Ku70 proteolysis. In this study, we focused on Ku70 ubiquitination in cells treated with genotoxic stress. Our observations do not exclude the 
a
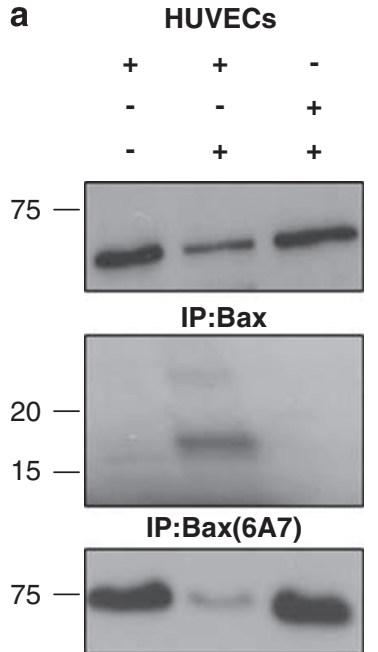

Cont. Virus

Myc-Myr-Akt

Etoposide

WB:Ku70

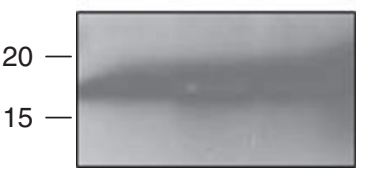

Input (Ku70)

WB: Bax

C

Growth/Survival Factor (e.g. VEGF)

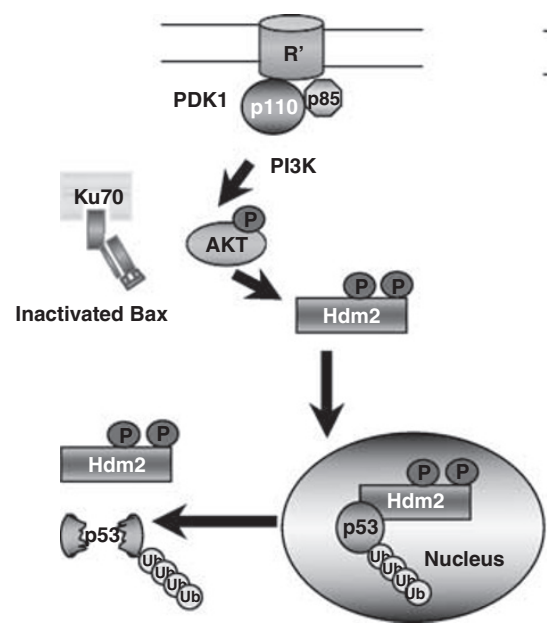

Input (Bax) b

ku70-/-MEFs

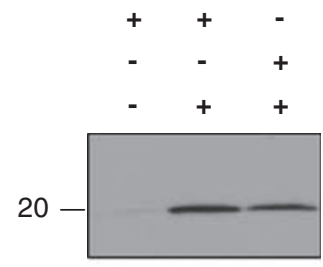

Cont. Virus

Myc-Myr-Akt

Etoposide

WB:Bax

IP:Bax(6A7)

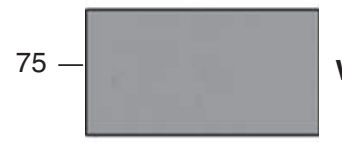

WB:Ku70

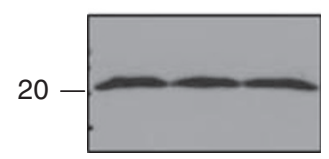

WB:Bax

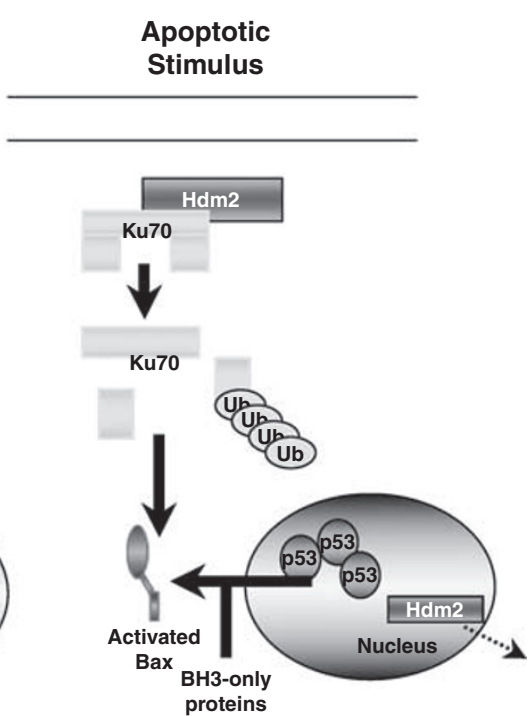

Figure 8 Akt inhibits apoptosis by maintaining Ku70-Bax interaction. (a) Akt maintained Ku70-Bax interaction in etoposide-treated HUVECs. HUVECs were infected with control adenovirus or adenovirus expressing Myc-Myr-Akt. The next day, cells were treated with $20 \mu \mathrm{M}$ etoposide for $8 \mathrm{~h}$. Cells were then lysed and Ku70 (top panel) was coimmunoprecipitated by anti-Bax polyclonal antibody (detecting both conformationally inactive and active Bax). Activated Bax (second panel) was immunoprecipitated by $6 \mathrm{~A} 7$ monoclonal antibody (detecting conformationally active Bax). Western blot analysis with anti-Ku70 monoclonal (top and third panels) or anti-Bax polyclonal antibody (N20) (second and fourth panels) was performed. The levels of Ku70 and Bax in cells in each condition are shown in the third and fourth panels. (b) Ku70 ${ }^{-1-}$ MEFs were treated as described for Right Panel experiments, and active Bax was immunoprecipitated by 6A7 monoclonal Ab. Immunoprecipitated Bax was detected by western blot using Bax polyclonal Ab. Ku70 and Bax levels in each sample are shown in the second and third panels, respectively. Similar experiments were performed three times, and one of them is shown in Supplementary Figure 4. (c) Hypothesized model for Ku70 regulation by Hdm2 and Akt. In the presence of growth/survival factor signals (left scheme), Ku70 levels are high enough to suppress Bax activation. Akt promotes Hdm2 translocation to the nucleus and induces the targeting of p53 for degradation. In the presence of apoptotic signals without active Akt signals (right scheme), Hdm2 remains in the cytosol and it targets Ku70 for degradation. This condition allows the release of Bax from inhibition, and Bax is activated by activators such as $\mathrm{BH} 3$ only proteins that are activated by $\mathrm{p} 53$

possibility of the existence of other Ku70 Ub ligase(s) that regulates $\mathrm{Ku} 70$ activities in response to challenges other than genotoxic stress. In addition to poly-ubiquitination, ${ }^{17}$ other post-translational modifications of Ku70, such as acetylation, ${ }^{9}$ phosphorylation (reviewed by Morio and $\mathrm{Kim}^{14}$ ), and mono-ubiquitination, ${ }^{25}$ have been reported. Further studies investigating the impacts of these modifications on Ku70 stability will increase our understanding of the multiple roles of Ku70 in controlling cellular life and genomic stability. 


\section{Materials and Methods}

Cell culture and detection of apoptosis. HeLa, human embryonic kidney (HEK) 293, and HEK293 T cells (obtained from ATCC) were cultured in DMEM (Dulbecco's Modified Eagle's medium) supplemented with $10 \%$ fetal bovine serum (FBS) and 1\% L-glutamine. H1299 cells and MEFs were cultured in DMEM supplemented with $10 \%$ FBS, $1 \%$ L-glutamine, $1 \%$ sodium pyruvate, and $1 \%$ nonessential amino acids. HUVECs were isolated from freshly obtained human umbilical cords (from three different donors) by collagenase digestion of the interior of the umbilical vein. These cells were used up to passage 7. HUVECs were cultured in EC growth medium plus supplements $\left(\mathrm{EGM}^{\mathbb{R}}-2\right.$-Endothelial Cell Medium-2 (Lonza, Switzerland)). Apoptosis was induced by treatment with $10-25 \mu \mathrm{M}$ etopo, $1 \mu \mathrm{M}$ doxorubicin, or $200 \mathrm{nM}$ STS as indicated in figure legends. One or two days after treatment, cells were stained with Hoechst dye, and apoptotic nuclei were counted by fluorescence microscopy ( 300 cells were counted for each experiment) as before. ${ }^{6}$ Plasmid transfection was performed with Lipofectamine Plus according to the manufacturers instructions, except HUVECs. Lipofectamine-LTX/Plus was used for the transient transfection of HUVECs.

Antibodies and reagents. Rabbit polyclonal antibody to human Ku70 ( $\mathrm{H}-308)$, mouse monoclonal antibody to human $\mathrm{Ku} 70$ (N3H10), mouse monoclonal to human Ku80 (B-1), rabbit polyclonal to human Ku80 (H300), and mouse monoclonal anti-ubiquitin antibody (P4D1) were purchased from Santa Cruz Biotechnology (St Louis, MO, USA); mouse monoclonal actin antibody was from Santa Cruz Biotechnology. Hdm2 antibody (2A10) and (IF2) were purchased from Calbiochem (San Diego, CA, USA). VEGF was purchased from R\&D Systems (Minneapolis, MN, USA). For the detection of Flag-tagged Ku70, anti-Flag antibody from Stratagene (Cedar Creek, TX, USA) was used. Additional reagents were purchased from the following sources: protein-A sepharose CL-4B, Amersham Pharmacia Biotech (Piscataway, NJ, USA); Caspase Inhibitor (z-VAD-fmk), Calbiochem; and ECL Western blotting detection reagents, Amersham Biosciences (Buckinghamshire, England).

Immunoprecipitation and immunoblotting. Adherent cells in $10-\mathrm{cm}$ dishes were collected by scraping and pelleted at 1000 r.p.m. Hermle Z400K centrifuge for $10 \mathrm{~min}$ at $4^{\circ} \mathrm{C}$. Cell pellets were then lysed in ice-cold $\left(4^{\circ} \mathrm{C}\right) \mathrm{CHAPS}$ buffer ( $150 \mathrm{mM} \mathrm{NaCl}, 10 \mathrm{mM}$ HEPES, pH 7.4 , and $1 \%$ CHAPS) or RIPA buffer (phosphate-buffered solution (PBS), $1 \%$ Nonidet P-40, $0.1 \%$ sodium dodecyl sulfate, $0.5 \%$ sodium deoxycholate) containing protease inhibitors (protease inhibitor cocktail, Sigma P8340, diluted 1:100), and $1 \mathrm{mM}$ phenylmethylsulfonyl fluoride (PMSF). Lysates were transferred to microcentrifuge tubes and centrifuged at 14000 r.p.m. (Hermle Z233 MK2 centrifuge) for $30 \mathrm{~min}$ at $4^{\circ} \mathrm{C}$ to remove the insoluble fraction. These lysates were used for western blot analysis. Immunoprecipitation experiments were performed by incubating $200 \mu \mathrm{l}$ of $5 \mu \mathrm{g} / \mu \mathrm{l}$ lysate protein with $20 \mu \mathrm{l}$ protein A sepharose, pre-absorbed with $2 \mu \mathrm{g}$ anti-Ku70 polyclonal antibody (H308), or anti-Ku80 polyclonal antibody at $4{ }^{\circ} \mathrm{C}$ for $2 \mathrm{~h}$. Two micrograms normal rabbit immunoglobulin $\mathrm{G}(\mathrm{lgG})$ were used as a negative control. After three times washing by buffer, the sepharose beads were boiled in $40 \mu \mathrm{l}$ of Laemmli loading buffer and $20 \mu \mathrm{l}$ of the eluted proteins were resolved by sodium dodecyl sulfate-polyacrylamide gel electrophoresis (SDS-PAGE). After SDS-PAGE, western blot analyses were performed using anti-Ku70 antibody (1:1000), or antiKu80 antibody $(1: 2000)$, as indicated in the figure legends.

For detecting the active form of Bax. HUVECs or ku70-/- MEFs in 10-cm dishes were lysed in $200 \mu$ l Chaps buffer containing protease inhibitors and PMSF. Immunoprecipitation was performed by incubating $200 \mu$ l of the lysates with $2 \mu \mathrm{g}$ of anti-Bax monoclonal antibody (clone $6 \mathrm{~A} 7, \mathrm{BD}-\mathrm{Pharmingen}$ ) at $4^{\circ} \mathrm{C}$ for $2 \mathrm{~h}$. Immunocomplexes in $200 \mu \mathrm{l}$ of the lysates were precipitated with $20 \mu \mathrm{l}$ protein A-sepharose. After three times washing with buffer, beads were boiled in $40 \mu \mathrm{l}$ Laemmli buffer and $20 \mu \mathrm{l}$ of the eluted proteins were analyzed by western blotting. Western blotting analysis of pre-immunoprecipitation (Input) and immunoprecipitated (IP) samples was performed with an anti-Bax polyclonal antibody $(\mathrm{N}-20$, sc-493; Santa Cruz).

For detecting Bax-Ku70 interactions. Human umbilical vein endothelial cells in 10-cm dishes were lysed in $200 \mu$ l Chaps buffer containing the protease inhibitors and PMSF. Immunoprecipitation was performed by incubating $200 \mu \mathrm{l}$ of the lysates with $2 \mu \mathrm{g}$ of monoclonal anti-Bax antibody (B9, Santa Cruz) or $2 \mu \mathrm{g}$ of monoclonal anti-Ku70 antibody (A9, Santa Cruz) at $4^{\circ} \mathrm{C}$ for $2 \mathrm{~h}$. Immunocomplexes in $200 \mu$ l of the lysates were precipitated with $20 \mu$ protein G-sepharose. After three times washing with buffer, beads were boiled in $40 \mu \mathrm{l}$ Laemmli buffer and $20 \mu \mathrm{l}$ of the eluted proteins were analyzed by western blotting. Mouse IgG was used as negative control. Western blot analysis of pre-immunoprecipitation (Input) and IP samples was performed with an anti-Ku70 polyclonal antibody (H-308, sc-9033; Santa Cruz) or an anti-Bax polyclonal antibody (N-20, sc-493; Santa Cruz).

In vitro ubiquitination assays. Reaction volumes of $50 \mu$ containing $40 \mathrm{mM}$ Tris- $\mathrm{HCl}(\mathrm{pH} 7.5), 5 \mathrm{mM} \mathrm{MgCl}$, 2 mM ATP, $2 \mathrm{mM}$ DTT, $40 \mathrm{nM}$ human Ub-activating enzyme, $150 \mathrm{nM} \mathrm{HsUbc5a,} 400 \mathrm{nM} \mathrm{Ku70} \mathrm{(Enzymax} \mathrm{LLC,} \mathrm{Lexington,} \mathrm{KY,} \mathrm{USA),} \mathrm{and}$ $400 \mathrm{nM}$ glutathione $S$-transferase (GST)-Hdm2 were incubated for $2 \mathrm{~h}$ at $37^{\circ} \mathrm{C}$ in the presence or absence of $10 \mu \mathrm{M}$ unlabeled $\mathrm{Ub}$. Reactions were quenched with $50 \mu \mathrm{l}$ of Laemmli sample buffer containing $2 \%$ (v/v) B-mercaptoethanol and boiled for $5 \mathrm{~min}$.

RNA interference. HeLa cells were plated onto six-well plates at $1.2 \times 10^{5}$ cells per well and transfected with the indicated siRNAs as described.$^{25}$ Forty-eight hours post-transfection, cells were harvested for western blot analysis. Cells were lysed at $4^{\circ} \mathrm{C}$ with ice-cold RIPA buffer containing $1 \mathrm{mM}$ sodium orthovanadate, protease inhibitor cocktail, and $1 \mathrm{mM}$ PMSF. Samples were then analyzed by western blotting. Annealed siRNAs against Ku70 sense strand 50-GGAAGAGAUAGUUUGAUUUTT-30, antisense strand 50-AAAUCAAACUA UCUCUUCCTG-30, and silencer negative control no. 1 siRNA were purchased from Ambion.

GST pulldowns. To examine the binding of Ku70 with GST-Hdm2 in vitro, the GST pull-down experiments were performed by using the ProFound ${ }^{\mathrm{TM}}$ pull-down GST protein/protein interaction kit (Pierce) as described by the manufacturer. The bound proteins were eluted, denatured in sample buffer, separated by $4-15 \%$ SDSPAGE and were detected by western blot analysis using anti-Ku70 antibodies.

Immunocytochemistry. Human umbilical vein endothelial cells were seeded on gelatin-coated $35-\mathrm{mm}$ dishes. Cells were serum-starved for $15 \mathrm{~min}$ and treated with VEGF (100 $\mathrm{ng} / \mathrm{ml}$ dissolved in serum-free medium) for $2 \mathrm{~h}$. Doxorubicin was then added for additional $2 \mathrm{~h}$. Immunofluorescence was carried out as described earlier. ${ }^{21}$ After fixation of samples in $4 \%$ paraform aldehyde (PFA) for $10 \mathrm{~min}$ and permeabilization with $0.2 \%$ Triton $\mathrm{X}-100$, the cellular localization of $\mathrm{Hdm} 2$ was detected using a monoclonal antibody against Mdm2 (IF2). After five times washing by PBS, the samples were further incubated with Texas-Red-conjugated goat antimouse $\lg G$ and examined under a fluorescent microscope.

Adenovirus. Adenovirus vectors that direct the expression of Myc-Myr-Akt (constitutively active Akt), Myc-K179M-Akt (dominant-negative Akt) (Admax-MycAkt $^{\text {Myr }}$ and Admax-Myc-Akt ${ }^{\mathrm{K} 179 \mathrm{M}}$ ) were described earlier. ${ }^{40}$ Virus content was calculated by the optical density of the samples at $260 \mathrm{~nm}$ using the relationship of $10^{12}$ virus particles per ml per $\mathrm{OD}_{260}$ unit as reported. ${ }^{40}$ HUVECs or HeLa cells were infected with 1:200 dilution of stock adenovirus for $16 \mathrm{~h}$. Cells were then washed three times in Hank's balance saline solution (HBSS) and cultured for $24 \mathrm{~h}$ in complete medium containing $20 \mu \mathrm{M}$ Etopo, $1 \mu \mathrm{M}$ doxorubicin, or $200 \mathrm{nM} \mathrm{STS}$. Then apoptosis was detected as described earlier, and cells were lysed at $4^{\circ} \mathrm{C}$ with icecold RIPA buffer containing $1 \mathrm{mM}$ sodium orthovanadate, protease inhibitor cocktail, and $1 \mathrm{mM}$ PMSF. Samples were then analyzed by western blotting.

Acknowledgements. This work was supported by fellowships from American Heart Association to Vivian Gama and Jose Gomez, Case Comprehensive Cancer Center Pilot Grant, and NIH R01AG031903 to Shigemi Matsuyama. We appreciate Dr. Mohanish Deshmukh for his generous support to allow the first author to perform some experiments in his laboratory.

1. Jacobson MD, Weil M, Raff MC. Programmed cell death in animal development. Cell 1997; 88: $347-354$

2. Wei MC, Zong WX, Cheng EH, Lindsten T, Panoutsakopoulou V, Ross AJ et al. Proapoptotic BAX and BAK: a requisite gateway to mitochondrial dysfunction and death. Science 2001; 292: 727-730.

3. Nechushtan A, Smith CL, Hsu YT, Youle RJ. Conformation of the Bax C-terminus regulates subcellular location and cell death. EMBO J 1999; 18: 2330-2341.

4. Scorrano L, Korsmeyer SJ. Mechanisms of cytochrome $c$ release by proapoptotic BCL-2 family members. Biochem Biophys Res Commun 2003; 304: 437-444.

5. Yoshida T, Tomioka I, Nagahara T, Holyst T, Sawada M, Hayes $P$ et al. Bax-inhibiting peptide derived from mouse and rat Ku70. Biochem Biophys Res Commun 2004; 321 961-966. 
6. Li Y, Yokota T, Gama V, Yoshida T, Gomez JA, Ishikawa K et al. Bax-inhibiting peptide protects cells from polyglutamine toxicity caused by Ku70 acetylation. Cell Death Differ 2007; 14: 2058-2067.

7. Gomez JA, Gama V, Yoshida T, Sun W, Hayes P, Leskov K et al. Bax-inhibiting peptides derived from Ku70 and cell-penetrating pentapeptides. Biochem Soc Trans 2007; 35: 797-801.

8. Yu LY, Jokitalo E, Sun YF, Mehlen P, Lindholm D, Saarma M et al. GDNF-deprived sympathetic neurons die via a novel nonmitochondrial pathway. J Cell Biol 2003; 163: 987-997.

9. Cohen HY, Lavu S, Bitterman KJ, Hekking B, Imahiyerobo TA, Miller C et al. Acetylation of the $\mathrm{C}$ terminus of Ku70 by CBP and PCAF controls Bax-mediated apoptosis. Mol Cell 2004; 13: 627-638.

10. Rashmi R, Kumar S, Karunagaran D. Ectopic expression of Bcl-XL or Ku70 protects human colon cancer cells (SW480) against curcumin-induced apoptosis while their downregulation potentiates it. Carcinogenesis 2004; 25: 1867-1877.

11. Subramanian C, Opipari Jr AW, Bian X, Castle VP, Kwok RP. Ku70 acetylation mediates neuroblastoma cell death induced by histone deacetylase inhibitors. Proc Natl Acad Sci USA 2005; 102: 4842-4847.

12. lijima K, Muranaka C, Kobayashi J, Sakamoto S, Komatsu K, Matsuura S et al. NBS regulates a novel apoptotic pathway through Bax activation. DNA Repair (Amst) 2008; 7 : 1705-1716.

13. Sundaresan NR, Samant SA, Pillai VB, Rajamohan SB, Gupta MP. SIRT3 is a stress responsive deacetylase in cardiomyocytes that protects cells from stress-mediated cell death by deacetylation of $\mathrm{Ku}-70$. Mol Cell Biol 2008; 28: 6384-6401.

14. Morio $\mathrm{T}, \mathrm{Kim} \mathrm{H}$. Ku, Artemis, and ataxia-telangiectasia-mutated: signalling networks in DNA damage. Int J Biochem Cell Biol 2008; 40: 598-603.

15. Gomez JA, Gama V, Matsuyama S. Cell-permeable penta-peptides derived from Baxinhibiting peptide. Cell Penetrating Peptide 2006, 2nd edn, pp 469-481, CRC Press.

16. Li Y, Yokota T, Gama V, Yoshida T, Gomez JA, Ishikawa K et al. Bax-inhibiting peptide protects cells from polyglutamine toxicity caused by Ku70 acetylation. Cell Death Differ 2007; 14: 2058-2067.

17. Gama V, Yoshida T, Gomez JA, Basile DP, Mayo LD, Haas AL et al. Involvement of the ubiquitin pathway in decreasing Ku70 levels in response to drug-induced apoptosis. Exp Cell Res 2006; 312: 488-499.

18. Cohen HY, Miller C, Bitterman KJ, Wall NR, Hekking B, Kessler B et al. Calorie restriction promotes mammalian cell survival by inducing the SIRT1 deacetylase. Science 2004; 305 390-392.

19. Haupt $Y$, Maya R, Kazaz A, Oren M. Mdm2 promotes the rapid degradation of p53. Nature 1997; 387: 296-299.

20. Kubbutat MH, Jones SN, Vousden KH. Regulation of $\mathrm{p} 53$ stability by Mdm2. Nature 1997 387: 299-303.

21. Mayo LD, Donner DB. A phosphatidylinositol 3-kinase/Akt pathway promotes translocation of Mdm2 from the cytoplasm to the nucleus. Proc Natl Acad Sci USA 2001; 98 11598-11603.

22. Ashcroft M, Ludwig RL, Woods DB, Copeland TD, Weber HO, MacRae EJ et al. Phosphorylation of HDM2 by Akt. Oncogene 2002; 21: 1955-1962.
23. Mayo LD, Donner DB. The PTEN, Mdm2, p53 tumor suppressor-oncoprotein network. Trends Biochem Sci 2002; 27: 462-467.

24. Miyashita T, Reed JC. Tumor suppressor p53 is a direct transcriptional activator of the human bax gene. Cell 1995; 80: 293-299.

25. Martinez J, Seveau S, Veiga E, Matsuyama S, Cossart P. Ku70, a component of the DNAdependent protein kinase, acts as a receptor involved in Rickettsia conorii invasion of mammalian cells. Cell 2005; 123: 1013-1023.

26. Meek DW, Knippschild U. Posttranslational modification of MDM2. Mol Cancer Res 2003; 1: 1017-1026.

27. Uldrijan S, Pannekoek WJ, Vousden KH. An essential function of the extreme C-terminus of MDM2 can be provided by MDMX. EMBO J 2007; 26: 102-112.

28. Carvajal D, Tovar C, Yang H, Vu BT, Heimbrook DC, Vassilev LT. Activation of p53 by MDM2 antagonists can protect proliferating cells from mitotic inhibitors. Cancer Res 2005; 65: 1918-1924.

29. Jiang M, Pabla N, Murphy RF, Yang T, Yin XM, Degenhardt K et al. Nutlin-3 protects kidney cells during cisplatin therapy by suppressing Bax/Bak activation. J Biol Chem 2007; 282: 2636-2645.

30. Vassilev LT. MDM2 inhibitors for cancer therapy. Trends Mol Med 2007; 13: 23-31.

31. Gerber HP, McMurtrey A, Kowalski J, Yan M, Keyt BA, Dixit V et al. Vascular endothelial growth factor regulates endothelial cell survival through the phosphatidylinositol $3^{\prime}$-kinase/ Akt signal transduction pathway. Requirement for Flk-1/KDR activation. J Biol Chem 1998; 273: 30336-30343.

32. Zhou BP, Liao Y, Xia W, Zou Y, Spohn B, Hung MC. HER-2/neu induces p53 ubiquitination via Akt-mediated MDM2 phosphorylation. Nat Cell Biol 2001; 3: 973-982.

33. Singleton BK, Priestley A, Steingrimsdottir H, Gell D, Blunt T, Jackson SP et al. Molecula and biochemical characterization of xrs mutants defective in Ku80. Mol Cell Biol 1997; 17: 1264-1273.

34. Gu Y, Jin S, Gao Y, Weaver DT, Alt FW. Ku70-deficient embryonic stem cells have increased ionizing radiosensitivity, defective DNA end-binding activity, and inability to support V(D)J recombination. Proc Natl Acad Sci USA 1997; 94: 8076-8081.

35. Bond GL, Hu W, Bond EE, Robins H, Lutzker SG, Arva NC et al. A single nucleotide polymorphism in the MDM2 promoter attenuates the p53 tumor suppressor pathway and accelerates tumor formation in humans. Cell 2004; 119: 591-602.

36. Jones SN, Hancock AR, Vogel H, Donehower LA, Bradley A. Overexpression of Mdm2 in mice reveals a p53-independent role for Mdm2 in tumorigenesis. Proc Natl Acad Sci USA 1998; 95: 15608-15612.

37. Manning BD, Cantley LC. AKT/PKB signaling: navigating downstream. Cell 2007; 129: 1261-1274.

38. Yamaguchi $\mathrm{H}$, Wang $\mathrm{HG}$. The protein kinase PKB/Akt regulates cell survival and apoptosis by inhibiting Bax conformational change. Oncogene 2001; 20: 7779-7786.

39. Tsuruta F, Masuyama N, Gotoh Y. The phosphatidylinositol 3-kinase (PI3K)-Akt pathway suppresses Bax translocation to mitochondria. J Biol Chem 2002; 277: 14040-14047.

40. Song K, Wang H, Krebs TL, Danielpour D. Novel roles of Akt and mTOR in suppressing TGF-beta/ALK5-mediated Smad3 activation. EMBO J 2006; 25: 58-69.

Supplementary Information accompanies the paper on Cell Death and Differentiation website (http://www.nature.com/cdd) 